\title{
Correlation between Antioxidant Activity and the Garcinol Content Released from Fruit Rinds of Endemic Garcinia quaesita Pierre on Different Cooking Conditions
}

\author{
Donisha Shani Niharika Keembiya Liyanagamage $\mathbb{D}^{1},{ }^{1,2}$ Susanthi Jayasinghe $\mathbb{D}^{1}{ }^{1}$ \\ Anoja Priyadarshani Attanayake $\left(\mathbb{b},{ }^{3}\right.$ and Veranja Karunaratne $\mathbb{C}^{1}$ \\ ${ }^{1}$ Department of Chemistry, Faculty of Science, University of Peradeniya, Peradeniya, Sri Lanka \\ ${ }^{2}$ Postgraduate Institute of Science, University of Peradeniya, Peradeniya, Sri Lanka \\ ${ }^{3}$ Department of Biochemistry, Faculty of Medicine, University of Ruhuna, Galle, Sri Lanka \\ Correspondence should be addressed to Susanthi Jayasinghe; susanthij@pdn.ac.lk
}

Received 20 July 2019; Accepted 23 December 2019; Published 28 February 2020

Academic Editor: Antoni Szumny

Copyright (c) 2020 Donisha Shani Niharika Keembiya Liyanagamage et al. This is an open access article distributed under the Creative Commons Attribution License, which permits unrestricted use, distribution, and reproduction in any medium, provided the original work is properly cited.

\begin{abstract}
The antioxidant activity of garcinol has been identified as the basis for various bioactivities in it, and the genus Garcinia is the main source for the garcinol. G. quaesita, which is endemic to Sri Lanka, is a representative member of genus Garcinia, and the dried fruit rind of G. quaesita is used practically in all curry preparations to impart a sour flavor. In our study, garcinol was isolated (yield: 3.67\%) from the dried fruit rind of G. quaesita, for the first time. Further, how cooking conditions enable the ingestion of garcinol during the consumption of curries was also examined. The garcinol content released in different cooking conditions was positively correlated with the antioxidant activity in vitro. The results revealed that boiling virgin coconut oil extract of G. quaesita, simulating the common practice of oil frying during cooking, is the best method for obtaining the highest amount of garcinol into the curry medium.
\end{abstract}

\section{Introduction}

Oxidative stress-mediated events are considered to be the most important unifying pathogenic factors responsible for most of the noncommunicable diseases such as diabetes mellitus, coronary heart disease, and cancer [1]. The high antioxidant capacity of phytochemicals is considered to be the hidden miracle responsible for the health benefits associated with most of the food varieties including fruits, vegetables, and spices [2]. It has been shown that there is a strong relationship between consumption of plant-derived food and the protection against degenerative diseases as the antioxidants facilitate free-radical scavenging activity, transition-metal chelating activity, or singlet-oxygen quenching capacity [3-6]. There is substantial evidence for the therapeutic role of spices that offer antioxidants, which prevent the oxidation of other compounds or neutralize free radicals [7]. Among the many natural antioxidants, garcinol has been identified as a good source of natural antioxidant as well as a potent bioactive compound that can be incorporated in the treatment of several degenerative diseases.

Garcinol is isolated from several species of the family Garcinia and was first isolated from the hexane extract of the dried fruit rind of G. indica [8]. Later, it was isolated from the bark of G. cambogia (G. gummi-gutta), fruits of G. cambogia (G. gummi-gutta), twig and leaves of G. bancana, bark of G. huillensis, pericarp of G. pedunculata, and leaves of $G$. travancorica [9-13]. The in vitro antioxidant activity studies done for garcinol by using electron spin resonance (ESR) spectrometry has shown that it has a potent radical scavenging activity [14]. Several studies on garcinol have revealed that it could exhibit the ability to fight many chronic diseases such as cardiovascular disorders, diabetes, neurodegenerative diseases, and asthma [15]. Further, it is 
found that garcinol inhibits growth of cancer cells and has the ability to modulate the expression of proinflammatory cytokines, inducible nitric oxide synthase (iNOS) and cyclooxygenase-2, NF- $\kappa$ B, STAT3, Akt, FAK, death receptors, nicotinic receptors, cyclin D3, and histone acetyltransferases (p300 and PCAF) [16-18]. In addition, oral administration of garcinol has reduced acute ulceration of the stomach in laboratory animals [19]. Furthermore, garcinol showed a clear neuroprotective effect associated with the antioxidant activity by inhibiting iNOS induction in astrocytes [20]. Despite the fact that garcinol has several prominent bioactivities, very few successful paths for the synthesis of garcinol are reported to date and hence, it is important to discover plants that would be a source of garcinol [21].

In the present study, we have revealed that Garcinia quaesita Pierre (Clusiaceae), an endemic species native to Sri Lanka, as a new source of garcinol. G. quaesita is locally known as "Rathgoraka," and dried fruit rinds are used to impart a sour flavor in the preparation of traditional curries as spices. G. quaesita is similar in vegetative morphology to G.gummi-gutta, which belongs to the same family. The dried fruit rinds of G.gummi-gutta (L.) N. Robson (formerly known as Garcinia cambogia) is used in the cuisines of Thailand, India, Burma, and Malaysia. Interestingly, in Sri Lanka, the dried rind of the fruit of G. quaesita has also been used in traditional medicine applications both as an astringent and as an antiseptic; ethnomedically, it is reported to act as a stomachic and is used in anorexia, chronic dyspepsia, hypertension, and dyslipidaemia [22]. Previously, Gunathilaka, Sriyani, and Sotheeswaran have reported the isolation of the bioactive compounds including quaesitol and harmonionic acid from the bark of $G$. quaesita [23]. However, to date, there is no published report on bioactivity studies and isolation of bioactive compound (s) from the fruit extract of G. quaesita grown in Sri Lanka.

Many changes occur in vegetables as well as in spices during the cooking process, and these cooking treatments soften the cell walls and facilitate the extraction of antioxidant molecules. Although published studies are available on the influence of cooking methods on the antioxidant activity of vegetables, there are limited studies on the effect of domestic cooking on spices [24]. The different cooking methods could encourage significant changes to the extraction of antioxidant molecules and affect the concentration of them in the cooking medium. The amount of the antioxidant active compounds released to curry medium depends on the conditions of the curry medium such as temperature, $\mathrm{pH}$, and the polarity of the medium [25]. Thus, it is important to identify the effective cooking method of spices for the extraction of high concentration of antioxidant molecules into the curry medium. This is specially a concern since the fruit rinds of G. queasita are not consumed unless it is used as a paste. The investigation of correlation between concentration of antioxidant molecules and the antioxidant activity in particular of the curry medium is also advantageous to understand a better cooking treatment.
Herein, we report the total antioxidant activity of fruit extracts of G. quaesita, in different solvents, the isolation and characterization of antioxidant compound (garcinol) from the active fraction (s) using bioassay-guided fractionation, and the correlation studies between total antioxidant activities of its dried fruit under simulated cooking conditions and isolated garcinol.

\section{Materials and Methods}

2.1. Chemicals and Instruments. (L)-Ascorbic acid, 1,1Diphenyl-2-picrylhydrazyl radical (DPPH), Folin-Ciocalteu reagent, and 2,4,6-Tris-(2-pyridyl)-1,3,5-triazine (TPTZ) were purchased from Sigma-Aldrich, USA. Solvents used for the HPLC analysis were HPLC grade. In addition, all other chemicals and solvents that were not mentioned above were analytical grade and were used without further purification.

UV spectra were recorded on a UV-Visible spectrophotometer (Shimadzu, Japan). ${ }^{1} \mathrm{H}$ and ${ }^{13} \mathrm{C}$ NMR spectra were recorded on a $400 \mathrm{~Hz}$ NMR spectrometer (Bruker, USA) using $\mathrm{CDCl}_{3}$. Melting points of the isolated compound were determined using a Stuart scientific electrothermal melting point apparatus and were uncorrected. The isolated compound was subjected to FTIR analysis for the determination of the functional groups present. A sample with $\mathrm{KBr}$ pelleted garcinol was used to obtain IR spectra in the scanning wave number ranging from 500 to $4000 \mathrm{~cm}^{-1}$ with a resolution of $4 \mathrm{~cm}^{-1}$ on FT-IR Spectrophotometer (Shimadzu, Japan). LC-MS spectra was recorded with LC-MS/ MS system (Waters, Milford, MA, USA) $(4.6 \times 150 \mathrm{~mm}$, $5 \mu \mathrm{m})$ at flow rate $0.3 \mathrm{~mL} \cdot \mathrm{min}^{-1}$ using acetonitrile: water (30\%). Data were acquired for precursor masses from $\mathrm{m} / \mathrm{z}$ $100-1500 \mathrm{amu}$ at $35 \mathrm{~K}$ resolution with data-dependent tandem mass spectrometry with both positive and negative modes. Digital polarimeter (M 241 Perkin-Elmer) was used to measure specific rotation of garcinol in ethanol. Further, a rotary evaporator (Buchi, Switzerland) was used in the preparation of plant extracts. The HPLC-UV/DAD analysis was carried for quantification of garcinol in different cooking methods on an Agilent 1100 (USA) $\left(\mathrm{C}_{18}\right.$ column $(4.6 \times 150 \mathrm{~mm}, 5 \mu \mathrm{m}))$.

2.2. Plant Material and Preparation of Plant Extracts. The dried fruit rinds of G. quaesita were collected from Kandy, Central Province, Sri Lanka, in March, 2016. The plant itself was taxonomically authenticated by comparing with specimens at the National Herbarium, National Botanical Gardens, Peradeniya, Sri Lanka.

A voucher specimen (No: 6/01/H/03) was deposited at National Herbarium, National Botanical Garden, Peradeniya, Sri Lanka. The dried fruit rinds were washed, oven dried $\left(60^{\circ} \mathrm{C}, 30\right.$ minutes), and ground into a fine powder. The resulting powder $(450.00 \mathrm{~g})$ was sequentially extracted into hexane, ethyl acetate, and methanol $(500 \mathrm{ml}, 3 \times 24$ hours) using an electrical shaker $\left(150 \mathrm{rpm}, 28^{\circ} \mathrm{C}\right)$. Solvents were evaporated under reduced pressure below $40^{\circ} \mathrm{C}$ using a rotary evaporator. Concentrated extracts were freeze- 
dried and the resultant powder was stored at $4^{\circ} \mathrm{C}$ until further use.

2.3. Evaluation of Antioxidant Activity. The DPPH radical scavenging activity was determined on the crude extracts of hexane, ethyl acetate, and methanol as mentioned below [26]. The $0.004 \%$ DPPH solution in methanol $(200 \mu \mathrm{L})$ was added to a graded concentration of the plant extract mixture $(2.8 \mathrm{~mL})$, and the reactants were incubated at $25^{\circ} \mathrm{C}$ for 30 minutes in the dark. L-ascorbic acid in methanol was used as the positive control. The absorbance was measured at $517 \mathrm{~nm}$ using a UV-visible spectrophotometer. The percentage of inhibition of DPPH radical scavenging activity of the tested samples was calculated as follows.

Percentage of inhibition $(\%)=\left(A_{0}-A_{1} / A_{0}\right) \times 100 \%$, where $A_{0}$ is the absorbance of the control and $A_{1}$ is the absorbance of the test (plant extract/reference compound). The concentration of plant extract mixture that inhibits the $50 \%$ of the DPPH radical formation $\left(\mathrm{IC}_{50}\right.$ ) was calculated using regression analysis.

The extract that showed the maximum antioxidant activity was used to isolate the antioxidant active compounds. Subsequently, DPPH radical scavenging activities of the isolated compound and cooked samples with dried rinds of G. quaesita were determined with same procedure as describe above.

Ferric reducing antioxidant power of isolated compound was estimated with the FRAP assay described by Benzie and Strain, with slight modifications [27]. The FRAP reagent was freshly prepared by adding $10 \mathrm{mM}$ of 2,4,6-Tris (2-pyridyl)1,3,5-triazine (TPTZ) dissolved in $40 \mathrm{mM}$ of $\mathrm{HCl}, 20 \mathrm{mM}$ of $\mathrm{FeCl}_{3}$ in water, and $300 \mathrm{mM}$ of acetate buffer (pH 3.6) in the ratio of $1: 1: 10$. Garcinol $(100 \mu \mathrm{L})$ was added to the FRAP reagent $(3.0 \mathrm{~mL})$ and mixed well. The absorbance of the resultant solution was measured at $593 \mathrm{~nm}$ using UV-visible spectrophotometer. $\mathrm{FeSO}_{4}$ served as the standard compound. The FRAP value was estimated using regression equation of $\mathrm{FeSO}_{4}$ standard curve and expressed in terms of ferrous equivalent (FE; concentration of the extract or standard compound that expresses the same absorbance as $1 \mathrm{mmol}$ of ferrous ion).

\subsection{TLC Bioautography Analysis and Isolation of Antioxidant} Compounds. The hexane extract of G. quaesita fruit rinds, which showed the highest antioxidant activity, was selected for the isolation of antioxidant compounds. An aliquot of crude hexane solution $(1 \mathrm{mg} / \mathrm{mL})$ was directly deposited as a spot on a TLC plate and developed with $n$-hexane:ethyl acetate $(7.5: 2.5)$. A solution of $0.004 \%(w / v)$ DPPH in methanol was sprayed on the developed TLC plate for derivatization [28].

Medium pressure liquid chromatography (MPLC) was performed on the crude hexane extract of G. quaesita $(4.50 \pm 0.05 \mathrm{~g})$. Nine fractions were obtained based on the TLC patterns, and the combined fractions were subjected to TLC bioautography with DPPH. The $5^{\text {th }}$ combined fraction showed comparatively high antioxidant activity and it was further separated using flash column chromatography. The resultant two fractions were subjected to the TLC bioautography with $\mathrm{DPPH}$, and the $2^{\text {nd }}$ fraction showed significant antioxidant activity. The most active target compound was isolated from the $2^{\text {nd }}$ fraction after subjecting to flash column chromatography (ethyl acetate: hexane $=7.5: 2.5$; yield:3.67\% from the crude hexane extract of fruits of G. quaesita, $4.50 \mathrm{~g}$ ). Based on comprehensive ${ }^{1} \mathrm{H}$ and ${ }^{13} \mathrm{C}$ NMR analysis, the structure of the isolated compound was elucidated as garcinol by comparing with reported data from literature [8]. In addition, it was subjected to the DPPH radical scavenging assay and ferric reducing antioxidant power (FRAP) assay.

\subsection{Preparation of Differently Processed Samples Simulating} Cooking Conditions. Homogeneous pieces of fruit rinds of G. quaesita $(50.0 \mathrm{~g}$ ) were immersed in $80.0 \mathrm{~mL}$ of each distilled water, distilled water and acetic acid solution $(\mathrm{pH}=4)$, distilled water and acetic acid solution $(\mathrm{pH}=2)$, and boiled for one hour to simulate the boiling of vegetables, fish, or meat in different acidic (strong and weak) environments that are generated with other added cooking ingredients such as vinegar. Same procedure was followed for natural coconut milk and saturated salt solution $(\mathrm{NaCl})$ to simulate the boiling of vegetables, fish, and meat with salt and coconut milk. The resultant aqueous extracts of $G$. quaesita were filtered and extracted into dichloromethane $(50 \mathrm{ml} \times 3)$ by liquid-liquid partition. Another two samples of $G$. quaesita ( $50.0 \mathrm{~g}$ ) were immersed in virgin coconut oil and treated with heat for one hour and stirred at room temperature for three hours to simulate pan frying (frying fish/meat) and mixing with oil without heating of vegetables. The resultant oil extractions were filtered and extracted into ethyl acetate $(50 \mathrm{ml} \times 3)$. Then, all organic solvents were evaporated using a rotary evaporator below $40^{\circ} \mathrm{C}$. The DPPH assay was performed on the resultant dried samples, and $\mathrm{IC}_{50}$ values were calculated. In addition, garcinol content was quantified using HPLC, and correlation analysis was done between the content of garcinol vs $\mathrm{IC}_{50}$ of DPPH assay.

2.6. HPLC Quantification of Garcinol Content in Cooked Samples. The HPLC-UV/DAD analysis was carried out on an Agilent 1100 (USA) connected to a diode array detector and controlled by Agilent software. An aliquot of each cooked sample was filtered and injected into the HPLC $\mathrm{C}_{18}$ column $(4.6 \times 150 \mathrm{~mm}, 5 \mu \mathrm{m})$ and eluted with a mobile phase containing acetonitrile: water in the ratio $7: 3$. The separation was carried out at room temperature $\left(27^{\circ} \mathrm{C}\right)$ and monitored at $360 \mathrm{~nm}$. The quantitative analysis of garcinol in each dried sample was achieved by peak area normalization.

2.7. Linearity. The linearity was determined by correlation coefficients of the analytical curves generated by injections of working solutions at eight concentration levels. In the method of quantification of garcinol in different cooked samples, an external standard method was employed using a stock solution of garcinol $(500.00 \pm 0.01 \mathrm{mg} / \mathrm{L})$ prepared in methanol. Eight working solutions with concentrations of 
$1.00-500.00 \pm 0.01 \mathrm{mg} / \mathrm{L}$ of garcinol were prepared by diluting the standard stock solution. The analytical curves were built by triplicate injections.

2.8. Statistical Analysis. All analyses/assays were done in triplicate. The results of the DPPH and FRAP assays were expressed as mean \pm SD. Minitab statistical software was used for the regression analysis and Pearson's correlation coefficient analysis between the concentration of garcinol and DPPH radical scavenging activity.

\section{Results and Discussion}

In the present study, the antioxidant activity for hexane, ethyl acetate, and methanol extracts of dried fruit rinds of G. quaesita was determined using DPPH radical scavenging assay, and the $\mathrm{IC}_{50}$ values of crude extracts were $8.74 \pm 0.75$, $77.36 \pm 0.82$, and $340.8 \pm 1.02 \mathrm{ppm}$, respectively. Interestingly, the highest antioxidant activity was observed in the crude hexane extract; hence, it was assumed that nonpolar compounds might be responsible for its activity. Even though the hexane extract of fruits of $G$. quaesita showed the highest antioxidant activity even better than the standard ascorbic acid, Shivapriya et al has reported that hexane extract of fruits of G. cambogia, which is similar in vegetative morphology to G. quaesita, showed very insignificant antioxidant activity [29]. The hexane extract that showed the highest antioxidant activity was selected for bioactivity-guided fractionation and isolation of antioxidant compounds in the present study. The active compounds present in the hexane extract were monitored using TLC bioautography in order to guide the separation as it allows rapid access for detection and localization of the active compounds in a plant extract. In this method, DPPH radical scavenging activity was observed visually as yellow spots on a purple background. This is a straightforward method to identify active fractions and to isolate antioxidant compounds. The fraction that showed the highest antioxidant activity was then further separated using silica gel flash column chromatography. Finally, one pure compound was isolated and subjected to structure elucidation.

The yellow crystalline compound isolated from hexane extract was identified as garcinol by UV, ${ }^{1} \mathrm{H}$ NMR, ${ }^{13} \mathrm{C}$ NMR, and LC-MS spectral data and by comparison with the literature data, $\mathrm{mp} 126^{\circ} \mathrm{C}, \mathrm{UV}$ in EtOH $(\log \epsilon) 256 \mathrm{~nm}$, $327 \mathrm{~nm}$; IR 3200-3500, 1730, $1640 \mathrm{~cm}^{-1}$; LC-MS was $\mathrm{m} / z$ 602 and $[\alpha]^{27}=-140^{\circ}$, Figure $1[8]$.

Even though garcinol has been isolated from several species of the family Garcinia, this is the first report on the isolation of garcinol from the hexane fruit extract of $G$. quaesita, an endemic plant native to Sri Lanka.

Garcinol showed concentration-dependent radical scavenging activity in the $\mathrm{DPPH}$ assay (expressed as $\mathrm{IC}_{50}$ values). The $\mathrm{IC}_{50}$ value of garcinol was $0.24 \pm 0.13 \mu \mathrm{g} / \mathrm{mL}$, while the standard antioxidant compound L-ascorbic acid achieved $10.10 \pm 0.07 \mu \mathrm{g} / \mathrm{mL}$. Although garcinol is known as an antioxidant compound, its comprehensive antioxidant activity in relation to its bioavailability under processing conditions has not been reported. The FRAP value of the isolated compound was found to be $740.85 \pm 0.01 \mu \mathrm{M}$ (Fe(II)/g compared to ascorbic acid with an FRAP value of $1206.00 \pm 0.06 \mu \mathrm{M}(\mathrm{Fe}(\mathrm{II}) / \mathrm{g}$. Garcinol is a polyisoprenylated benzophenone and chemically it is a tri-isoprenylated chalcone, and the antioxidant nature of garcinol largely depends on its polyphenolic structure.

The dried fruit of G. quaesita is a well-known spice used extensively in Sri Lankan and Asian daily curry preparations. The presence of large amounts of highly antioxidant active garcinol in the fruits of G. quaesita (yield; 3.67\%) from the crude hexane extract of fruits of G. quaesita can be used to unleash its health benefits. Therefore, our investigation is also focused on studying the scientific validation of the use of dried fruits of G. quaesita in curry preparations. The fruits of G. quaesita have been used in the several different simulated cooking methods in order to understand the effects of cooking conditions on the antioxidant efficiency of dried fruit rinds of $G$. quaesita. In addition, since garcinol is the main antioxidant compound in dried fruits of G. quaesita, quantification of garcinol content present was also carried out. Table 1 and Figure 2 show the $\mathrm{IC}_{50}$ values of differently processed samples of $G$. quaesita simulating cooking conditions applicable in the DPPH assay.

A garcinol calibration curve was developed acquiring chromatograms at $360 \mathrm{~nm}$ in the linearity range of 1-500 ppm. A reverse-phase HPLC analysis was performed in order to quantify the garcinol content. The garcinol content of the dried samples prepared from liquid-liquid partition was calculated using regression analysis $(Y=5.84 X+37.37)$ and is shown in Table 2 and Figure 3.

According to the observed data, the highest antioxidant activity was obtained for the nonpolar coconut oil medium, which is again correlated with the observed higher antioxidant activity of the crude hexane extract. The garcinol content showed a significant positive correlation with antioxidant activity of curry medium, with Pearson's correlation coefficients of $0.880\left(R^{2}=87.0 \%, p<0.05\right)$. It suggests that antioxidant activity of the curry medium that contains dried fruits of G. quaesita depends on the released garcinol content into the curry medium. Therefore, it reflects a strong relationship between antioxidant activity and the nature of the conditions in the curry medium. This linear relationship quantitatively confirms the significance of the garcinol content in the curry medium to the antioxidant activity. Further, in comparison to the antioxidant activity obtained for crude extracts of $G$. quaesita, hexane extract showed the highest antioxidant activity and garcinol was present there as the major compound. Thus, it can be rationalized that garcinol is responsible for the antioxidant activity in G. quaesita. The extract obtained from oil medium showed the highest antioxidant activity in the DPPH assay $(8.64 \pm 1.15$ and $6.73 \pm 1.29$ respectively) suggesting that the oil medium is more favorable to release nonpolar garcinol to the curry medium. Interestingly, the antioxidant activity in neutral aqueous medium also turned out to be relatively high $\left(\mathrm{IC}_{50}=15.86 \pm 0.1\right)$, suggesting that garcinol has the ability to be released into 




FIgURE 1: Structure of garcinol.

TABLE 1: $\mathrm{IC}_{50}$ values of differently processed extracts of G. quaesita simulating cooking conditions in DPPH assay.

Extract $\mathrm{IC}_{50}$ value in $\mathrm{DPPH}$ assay/ppm

Distilled water

Distilled water and acetic acid $(\mathrm{pH}=2)$

$15.86 \pm 0.1$

Distilled water and acetic acid $(\mathrm{pH}=4)$

$55.72 \pm 1.8$

Natural coconut milk

$44.72 \pm 0.4$

$34.78 \pm 1.0$

Virgin coconut oil (room temp)

$8.64 \pm 1.2$

Virgin coconut oil (boil)

$6.73 \pm 1.3$

Saturated salt solution

$70.42 \pm 2.0$

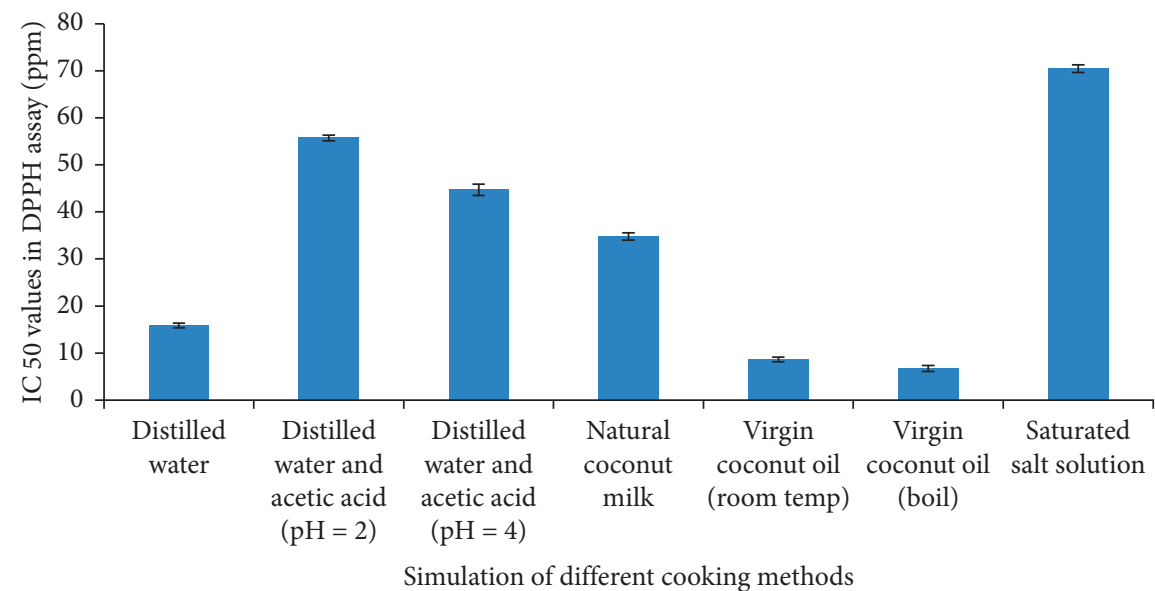

FIgURE 2: $\mathrm{IC}_{50}$ values for different cooking samples in DPPH assay. Each data point is the triplicate mean.

TABLe 2: Percentage of garcinol content in differently processed extracts of G. quaesita simulating cooking conditions.

\begin{tabular}{lccc}
\hline Extract & Area under the curve in HPLC & Content of garcinol (ppm) $^{\text {Percentage of garcinol }^{1}}$ \\
\hline Distilled water & $1612.29 \pm 1.65$ & 266 & 20 \\
Distilled water and acetic acid $(\mathrm{pH}=2)$ & $581.71 \pm 0.09$ & 96 & 7 \\
Distilled water and acetic acid $(\mathrm{pH}=4)$ & $835.52 \pm 0.04$ & 138 & 10 \\
Natural coconut milk & $109.36 \pm 1.03$ & 18 & 1 \\
Virgin coconut oil (at room temperature) & $2032.46 \pm 0.84$ & 436 & 25 \\
Virgin coconut oil (boil) & $2496.12 \pm 1.42$ & 5 & 30 \\
Saturated salt solution & $31.77 \pm 1.05$ & 1 & 1
\end{tabular}

\footnotetext{
${ }^{1}$ Percentage of garcinol calculated with respect to the weights of crude extracts obtained after the solvent extraction of each cooking sample.
} 


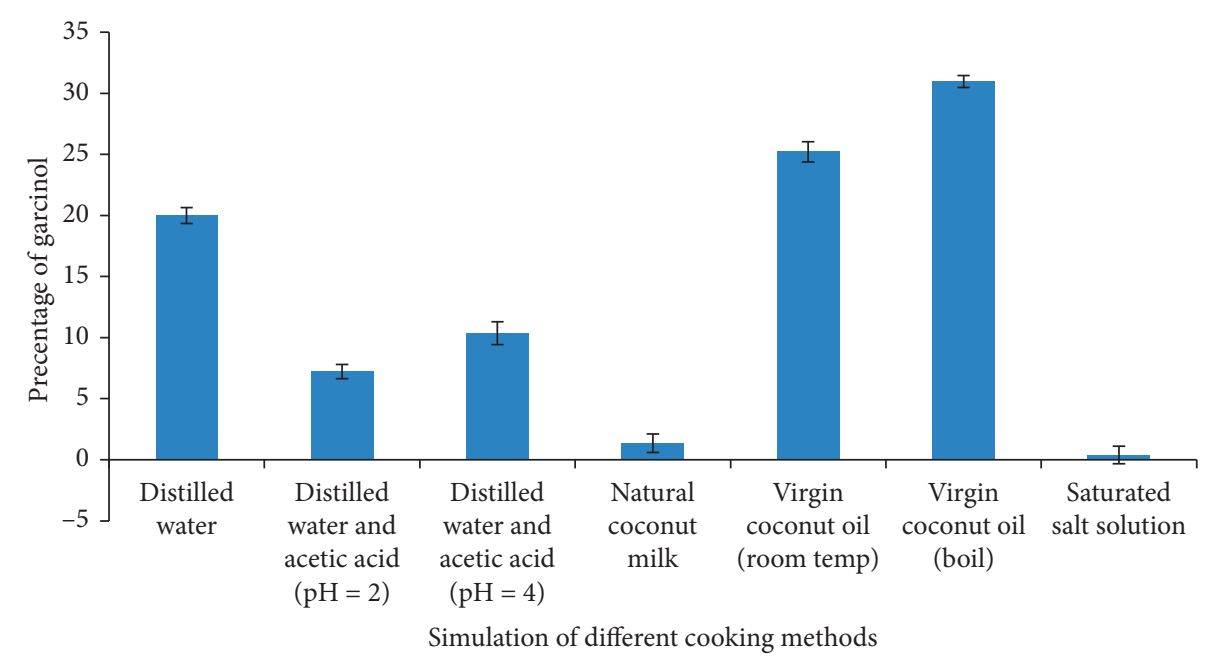

FIgURE 3: Percentage of garcinol content in different cooking samples. Each data point is the triplicate mean.

polar aqueous medium through its hydrophilic functional groups. Importantly, among the cooking conditions mentioned above, boiling virgin coconut oil extract simulating the oil frying method is the best method to obtain the highest antioxidant activity. However, since oil frying of curry mixtures is invariably laced with water, traditional cooking methods using G. quaesita could bring out garcinol both by oil and water. Hence, traditional cooking with G. quaesita using oil can be appreciated as a best practice to obtain the highest amount of garcinol leading to potentially higher bioavailability and positive health benefits. Unless it is a paste made out of fruit rinds of $G$. quaesita, the traditional practice is to remove the fruit rind of G. quaesita after cooking without consumption. Significantly, if an oil medium is used, garcinol may be released to the diet whether used as a paste or as the whole fruit rind. This is the first report on correlation study between the antioxidant activity of the different curry mediums that contain dried fruit rinds from Garcinia family and the garcinol content.

\section{Conclusions}

The results revealed that antioxidant activity is the highest in the hexane extract of dried fruit rinds of G. quaesita. It was confirmed that the predominant antioxidant compound in the hexane extract is garcinol. Garcinol exhibits a statistically significant in vitro antioxidant activity in DPPH and FRAP assays. The antioxidant activity of curry medium is greatly influenced by the nature of cooking conditions, and the best method to obtain highest amount of garcinol into the curry medium is the oil frying method followed closely by neutral aqueous medium. There is a positive correlation between garcinol content in different cooking conditions and the antioxidant activity in vitro. Thus, these results validated the traditionally practiced aqueous/oil frying for releasing maximum amount of garcinol leading to potent antioxidant activity-related health benefits.

\section{Data Availability}

The data used to support the findings of this study are available from the corresponding author upon request.

\section{Conflicts of Interest}

The authors declare no conflicts of interest.

\section{Acknowledgments}

This work was supported by University Research Grant B/ Sc/2016/CH/URG/52/S from the University of Peradeniya, Peradeniya, Sri Lanka.

\section{Supplementary Materials}

The yellow crystalline compound isolated from hexane extract was identified as garcinol by UV, ${ }^{1} \mathrm{H}$ NMR, ${ }^{13} \mathrm{C}$ NMR, and LC-MS spectral data and by comparison with the literature data, $\mathrm{mp} 126^{\circ} \mathrm{C}$, UV in EtOH $(\log \epsilon) 256 \mathrm{~nm}$, $327 \mathrm{~nm}$; IR 3200-3500, 1730, $1640 \mathrm{~cm}^{-1}$; LC-MS was $\mathrm{m} / z$ 602 and $[\alpha]^{27}=-140^{\circ}$ (Figure 1: ${ }^{1} \mathrm{H}$ NMR Spectrum for Garcinol, Figure 2: ${ }^{13} \mathrm{C}$ NMR Spectrum for Garcinol, and Figure 3; IR Spectrum for Garcinol). The identification of compound was substantiated by the presence of some characteristic proton and carbon signals on the ${ }^{1} \mathrm{H}$ NMR and ${ }^{13} \mathrm{C}$ NMR Spectra (Table 1). All the data above along with the UV, NMR, IR, and melting point agreed with reported garcinol characterization. (Supplementary Materials)

\section{References}

[1] U. Asmat, K. Abad, and K. Ismail, "Diabetes mellitus and oxidative stress-a concise review," Saudi Pharmaceutical Journal, vol. 24, no. 5, pp. 547-553, 2016.

[2] E. Opara and M. Chohan, "Culinary herbs and spices: their bioactive properties, the contribution of polyphenols and the challenges in deducing their true health benefits," 
International Journal of Molecular Sciences, vol. 15, no. 10, pp. 19183-19202, 2014.

[3] M. W. Gillman, L. A. Cupples, D. Gagnon et al., "Protective effect of fruits and vegetables on development of stroke in men," JAMA: The Journal of the American Medical Association, vol. 273, no. 14, pp. 1113-1117, 1995.

[4] C. La Vecchia, A. Altieri, and A. Tavani, "Vegetables, fruit, antioxidants and cancer: a review of Italian studies," European Journal of Nutrition, vol. 40, no. 6, pp. 261-267, 2001.

[5] P. Terry, J. B. Terry, and A. Wolk, "Fruit and vegetable consumption in the prevention of cancer: an update," Journal of Internal Medicine, vol. 250, no. 4, pp. 280-290, 2008.

[6] J. H. Cohen, A. R. Kristal, and J. L. Stanford, "Fruit and vegetable intakes and prostate cancer risk," Journal of the National Cancer Institute, vol. 92, no. 1, pp. 61-68, 2000.

[7] A. Yashin, Y. Yashin, X. Xia, and B. Nemzer, "Antioxidant activity of spices and their impact on human health: a review," Antioxidants, vol. 6, no. 3, p. 70, 2017.

[8] N. Krishnamurthy, Y. S. Lewis, and B. Ravindranath, "On the structures of garcinol, isogarcinol and camboginol," Tetrahedron Letters, vol. 22, no. 8, pp. 793-796, 1981.

[9] J. Kolodziejczyk, M. Masullo, B. Olas, S. Piacente, and B. Wachowicz, "Effects of garcinol and guttiferone $\mathrm{K}$ isolated from garcinia cambogiaon oxidative/nitrative modifications in blood platelets and plasma," Platelets, vol. 20, no. 7, pp. 487-492, 2009.

[10] V. Rukachaisirikul, W. Naklue, Y. Sukpondma, and S. Phongpaichit, "An antibacterial biphenyl derivative from garcinia bancana MIQ," Chemical \& Pharmaceutical Bulletin, vol. 53, no. 3, pp. 342-343, 2005.

[11] P. Bakana, M. Claeys, J. Totté et al., "Structure and chemotherapeutical activity of a polyisoprenylated benzophenone from the stem bark of Garcinia huillensis," Journal of Ethnopharmacology, vol. 21, no. 1, pp. 75-84, 1987.

[12] A. Sahu, B. Das, and A. Chatterjee, "Polyisoprenylated benzophenones from Garcinia pedunculata," Phytochemistry, vol. 28 , no. 4, pp. 1233-1235, 1989.

[13] A. P. Anu Aravind, K. R. T. Asha, and K. B. Rameshkumar, "Phytochemical analysis and antioxidant potential of the leaves of Garcinia travancoricaBedd," Natural Product Research, vol. 30, no. 2, pp. 232-236, 2016.

[14] F. Yamaguchi, T. Ariga, Y. Yoshimura, and H. Nakazawa, "Antioxidative and anti-glycation activity of garcinol from garcinia indica fruit rind," Journal of Agricultural and Food Chemistry, vol. 48, no. 2, pp. 180-185, 2000.

[15] A. K. Behera, M. M. Swamy, N. Natesh, and T. K. Kundu, "Garcinol and its role in chronic diseases," in Anti-Inflammatory Nutraceuticals and Chronic Diseases, pp. 435-452, Springer, Berlin, Germany, 2016.

[16] S. Prasad, J. Ravindran, B. Sung, M. K. Pandey, and B. B. Aggarwal, "Garcinol potentiates TRAIL-induced apoptosis through modulation of death receptors and antiapoptotic proteins," Molecular Cancer Therapeutics, vol. 9, no. 4, pp. 856-868, 2010.

[17] G. Sethi, S. Chatterjee, P. Rajendran et al., "Inhibition of STAT3 dimerization and acetylation by garcinol suppresses the growth of human hepatocellular carcinoma in vitro and in vivo," Molecular Cancer, vol. 13, no. 1, p. 66, 2014.

[18] A. Ahmad, S. H. Sarkar, B. Bitar et al., "Garcinol regulates EMT and WNT signaling pathways in vitro and in vivo, leading to anticancer activity against breast cancer cells," Molecular Cancer Therapeutics, vol. 11, no. 10, pp. 2193-2201, 2012.

[19] F. Yamaguchi, M. Saito, T. Ariga, Y. Yoshimura, and H. Nakazawa, "Free radical scavenging activity and antiulcer activity of garcinol from garcinia indica fruit rind," Journal of Agricultural and Food Chemistry, vol. 48, no. 6, pp. 23202325, 2000.

[20] C.-H. Liao, S. Sang, Y.-C. Liang, C.-T. Ho, and J.-K. Lin, "Suppression of inducible nitric oxide synthase and cyclooxygenase-2 in downregulating nuclear factor-kappa B pathway by garcinol," Molecular Carcinogenesis, vol. 41, no. 3, pp. 140-149, 2004.

[21] C. Socolsky and B. Plietker, "Total synthesis and absolute configuration assignment of MRSA active garcinol and isogarcinol," Chemistry-A European Journal, vol. 21, no. 7, pp. 3053-3061, 2015.

[22] D. M. A. Jayaweera, Medicinal Plants (Indigenous and Exotic) Used in Ceylon, The National Science Council of Sri Lanka, Colombo, Sri Lanka, 1980.

[23] A. A. L. Gunatilaka, H. T. B. Sriyani, and S. Sotheeswaran, "Quaesitol, a phenol from Garcinia quaesita," Phytochemistry, vol. 23, no. 11, pp. 2679-2681, 1984.

[24] A. M. Jiménez-Monreal, L. García-Diz, M. Martínez-Tomé, M. Mariscal, and M. A. Murcia, "Influence of cooking methods on antioxidant activity of vegetables," Journal of Food Science, vol. 74, no. 3, pp. H97-H103, 2009.

[25] M. Hęś, A. Gliszczyńska-Świgło, and A. GramzaMichałowska, "The effect of antioxidants on quantitative changes of lysine and methionine in linoleic acid emulsions at different $\mathrm{pH}$ conditions," Acta Scientiarum Polonorum Technologia Alimentaria, vol. 16, no. 1, pp. 53-67, 2017.

[26] M. S. Blois, "Antioxidant determinations by the use of a stable free radical," Nature, vol. 181, no. 4617, pp. 1199-1200, 1958.

[27] I. F. Benzie and J. J. Strain, "Ferric reducing antioxidant power assay: direct measure of total antioxidant activity of biological fluids and modified version for simultaneous measurement of total antioxidant power and ascorbic acid concentration," in Methods in Enzymology, vol. 299, pp. 15-27, Academic Press, Cambridge, MA, USA, 1999.

[28] L. Gu, T. Wu, and Z. Wang, "TLC bioautography-guided isolation of antioxidants from fruit of Perilla frutescens var. acuta," LWT-Food Science and Technology, vol. 42, no. 1, pp. 131-136, 2009.

[29] S. Shivakumar, S. Sandhiya, N. Subhasree, 1 A. Agrawa, and G. P. Dubey, "In vitro assessment of antibacterial and antioxidant activities of fruit rind extracts of Garcinia cambogia," International Journal of Pharmacy and Pharmaceutical Sciences, vol. 5, no. 2, pp. 254-257, 2013. 